\title{
5 Research Square

\section{Challenges faced during clinical placement among nursing students. A mixed study conducted at highest institutions in Addis Ababa city, Ethiopia, 2020}

\author{
Almaz Addisie \\ Addis Ababa University \\ Amsale Cherie \\ Addis Ababa University \\ Debela Gela \\ Addis Ababa University \\ Bizuayehu Atinafu Ataro ( $\sim$ bizuayehu.atinafu@aau.edu.et ) \\ Wolaita Sodo University
}

\section{Research Article}

Keywords: Clinical environment, Clinical practice, Clinical Setting challenges, BSC Nursing, students, Addis Ababa.

Posted Date: March 3rd, 2022

DOI: https://doi.org/10.21203/rs.3.rs-1376645/v1

License: (c) (i) This work is licensed under a Creative Commons Attribution 4.0 International License.

Read Full License 


\section{Abstract \\ Background}

The clinical learning environment is important to achieve the defined learning outcomes of the program, however nurse students face a multitude of challenges during their clinical placement.

\section{Objectives}

The objective of the study was to explore challenges experienced by nursing students during clinical placement with associated factors among highest institutions of Addis Ababa city, Ethiopia, 2020.

\section{Method}

A mixed method approach composed of cross sectional study and phenomenological method employed from February 15, to April 30, 2020 on 179 third- and fourth-year undergraduate nursing students selected using simple random sampling for the quantitative study and seven purposively selected students for qualitative study. Self-administered questionnaire and recording of telephone interview used to collect quantitative and qualitative data respectively. Logistic regression analysis carried out to identify the independent predictors, whereas the qualitative data analyzed using interpretation of the voice recorded during telephone interview, extracting significant statements, formulating meanings, and coding, categorizing into clusters of themes using the content analysis approach and using ATLAS ti.Version 7.5.16 software.

\section{Result}

the prevalence of challenge among nursing students was found to be 29 (16.9\%).Consequently, in bivariate logistic regression, students' religion, residence, entrance year, learning institution and substance use were found to have association with challenge among nursing student. However, in multivariable analysis only substance use and learning institution found to have significant association. Furthermore statistically significant negative moderate correlation between students total challenge score and their overall competency score were identified $[r=-0.672$, $P$ value $=<0.001]$. In qualitative content regards student Nurses factors, lack of role model, instructors responsibilities, inadequate support structure \& communication, lack of equipment and college responsibility were emerged.

\section{Conclusion}

It is essential to plan and improve students' clinical supervision and support at clinical setting by their instructors and staff nurses to create skillful nursing students and minimize their challenge. Therefore 
there should be adequate orientation and ongoing follow-up for students before internship by principal instructors.

\section{Background}

Nursing education is composed of two harmonizing parts: theoretical training and practical training. A vast part of nursing education is sustained out in clinical environments. In many countries, clinical education forms more than half of the proper educational courses in nursing. Thus, clinical education is central part of the nursing education program(5).Since nursing is a performance-based profession, clinical learning environments plays an essential part in the accomplishment of professional abilities. Further, the clinical area of nursing education has vital meaning for nursing students in the choice or rejection of nursing as a profession. Clinical teaching and learning is a complex environment affected by many factors nevertheless it provides a chance for nursing students to learn and understand theoretical knowledge and expand the mental, psychological, and psychomotor skills which are of significant for the patient care $(1,2,3,4,6,8,9)$.

Clinical learning environment is important to achieve the defined learning outcomes of the program(1) and includes the clinical settings, nursing staff, patients; nurse tutors etc. As having positive clinical environment affect the career choices of nursing students and quality of the clinical learning environment influence the achievement of the learning outcomes, a plan is required to select a best clinical learning environment, which is difficult to achieve (2).

As clinical environment is potential source of anxiety, disappointment and disgust, the link between the instructors, staff nurses and patients are very essential to form students' clinical training, to cope and reduce the real shock(1). Wherefore student nurses are required to develop different skills through clinical practice such as independence, critical thinking, communication, time management, responsibility with accountability and in developing clinical judgment, the quality of clinical learning is vital to ensure attaining the learning results via averting the upcoming institutional shock (3). An optimal clinical learning setting has a positive effect on the students' professional growth, whereas a poor learning setting can have contrary effects on their professional development process(10) and the erratic nature of clinical training environment can create some challenges to them (11).

The academics' experience in the nursing clinical instruction exposes students' behaviors and performances alteration in the clinical area, which in turn negatively affects their learning, development in a patient care, and professional act(11).Detecting problems and challenges students are faced in the clinical learning environment can help stakeholders solve these problems and contribute to them appropriate professional as well as their professional endurance(2).Incapable to recognize the challenges and problems the students are faced with in the clinical learning setting inhibits them from effective learning and progress, as a consequence, the progress and growth of their skills will be inclined (12).Studies show that the students' non-effective contact to the clinical learning environment 
has amplified failure rates, according to Wambui and Githui conclusion; some student nurses have gone from the profession as effect of challenges during their clinical area practice $(13,14,16)$.

Furthermore, the nursing students' shortage of knowledge and skills in the clinical environment can lead to anxiety(14), as a result; most novel bachelor graduates have reasonable theoretical knowledge but lack of competence in the clinical practice(11).To build up health systems function effectively with adequate figures of skilled, interested and reinforced nurses who show a good work ethics at all times, possible obstacles in clinical area practice need to be identified and halted(11).

The Clinical area where nurses acquire clinical skill, especially in sub-Saharan African situations is challenged by host of factors which can distress learning unfavorably(16). Some issues stated to distress students learning in clinical practice act are namely individual factors(student and nurse tutors factors),social-economic factors and hospital environment (17). A Study done in Botswana shown that nursing students failed to apply theory into practice because they had shortage adequate supervision in the clinical setting which effects less acquired in their clinical skill(6). Though the outcomes of some studies have showed the nurse instructors don't have the required effectiveness, knowledge and skills for teaching students, the extensive gap between theoretical and clinical teaching results from instructive planning methods in the field of nursing(9).

The magnitude of clinical training competency the conducted study in Ethiopia, on debt of factors affecting doing in clinical practice and competency of undergraduate related health science Students ,was, $25.2 \%$ and this finding is not consistent with the approach where Ethiopia governments want to achieve more than this percentage which is in creating competent professionals in term quality and number currently(16).This might be due to in quality of clinical practice being provided(16) and other socio-economic status of study participants. The common challenges experienced by the nursing student at clinical setting are broadly summarized into individual, health institution, clinical supervisor, and client related factors(18). Individual factors: that commonly shown to affect student nurses' attitude towards clinical practice include anxiety, attitude towards nursing profession, Learner's expectations and readiness and learner's Competence and Confidence Level(18).

A hospital is a significant learning environment for nursing students which is essential to the education of a nurse(18) and in a unit nursing students engage with patients who are a needy for a professional nursing care. Study done in Ghana reproved, clinical instructor factors and staff-student interaction factors were significantly associated with clinical practice competency whereas a Study done in Ethiopia came with, $58 \%$ of student nurses have favorable attitude towards clinical practice(3) but; some of them have unfavorable attitude towards clinical practice and majority of them reported a late coming to clinical practice makes them not adequately prepared for clinical practice (19), therefore more supportive and relevant intervention should be implemented to help them to achieve a higher level of clinical setting practice(20). 
There are various challenges that occur in nursing education in clinical setting perhaps exploring those challenges encountered by undergraduate nurses in term of clinical setting difficulties helps to identify the significant problems hindering the professional development and competence, advance a training and boost the quality of internship (15). Therefore, the current study carried out with the goal of identifying influential practical learning challenges and perception of nursing students on clinical environments.

\section{General Objectives}

The general objective of this study was to examine the challenges experienced by nursing student at the clinical placement, Addis Ababa, Ethiopia, 2020.

\section{Specific Objectives}

- To explore a challenges experienced by a nursing students during clinical placement.

- To identify the factors affecting clinical practice of nursing students in clinical placement.

- To assess the association between the factors and clinical practice competence.

\section{Methods}

\section{Study design, period and area}

A mixed method design imposed from February 15, to April 30, 2020. For further extension, cross sectional study and qualitative exploratory approach employed, phenomenological method also carried out to explore the lived experiences of student nurses during clinical practice.

A study was conducted in highest institutions of Addis Ababa city and major reason for selecting the site was because of its location; as it is located in a center and the capital city of the country where many high level public and private health colleges better equipped with personnel and high tech-equipment are found.

\section{Population}

Source population

All undergraduate nursing students who were assigned in health institutions of Addis Ababa city.

Study population

All third- and fourth-year undergraduate nursing students from public and private health colleges who were expected to isolate learning issues affecting their learning in their clinical learning setting during the study period.

\section{Inclusion criteria}


All $3^{\text {rd }}$ and $4^{\text {th }}$ under graduate nursing students who were attending their study under regular degree program in generic or upgrade level in public and private institutions collage and who were available at the time of data collection.

Those students who involved in more than one clinical practice experience.

\section{Exclusion criteria}

Midwifes, and public health officers.

\section{Sample size determination, techniques, procedures and variables}

The sample size was determined by using a formula for estimating a single population proportion formula. Simple random sampling technique was used for the selection of third- and fourth-year undergraduate nursing students. The prevalence of clinical practice competency of study participant (25.2\%) used to determine a sample size, $95 \%$ confidence interval (1.96) and 5\% standard error also considered in the equation to find out 179 students. A study population included all third- and fourth-year undergraduate nursing students $(n=373)$ and a phenomenological interview was generally understood to be less than 10 participants(37).

$p=25.2 \%(0.252)$ from previous research(28). $d=0.05$ degree of margin of error

$n=Z^{2} * P(1-P) / e^{2}$

$\mathrm{n}=1.96^{2} * 0.252 *(1-0.252) / 0.05^{2}=290$

$\mathrm{n}=290$

As a study population was less than 10,000 finite populations, a correction formula was applied:

$$
n_{r}=\frac{\mathrm{n}}{1+\left\{\frac{\mathrm{n}}{\mathrm{N}}\right\}}
$$

Where $\mathrm{n}=$ desired sample size

$n_{r}=$ the calculated sample size

$\mathrm{N}=$ Total population

$$
\begin{gathered}
n_{r}=\frac{290}{1+\left(\frac{290}{378}\right)} \\
n_{r}=163
\end{gathered}
$$

Adding $10 \%$ non-responsive rate, the total sample size required for this study appears to be 179 . 
Addis Ababa University School and Saint Paulos Millennium Medical College were selected from the public highest institutions. Whereas KEAMed medical college and St. Mery college of health sciences selected from private highest institutions.

The sample in the four highest institutions is 373 and a total sample size allocated to each institutions by proportion to the number of under graduate nursing students. Then study population selected using simple random sampling technique. Qualitative sample selected purposively as it is important in a sequential mixed methods designs in which a qualitative sample is drawn directly from the quantitative sample(38). Proportional allocation as shown below;

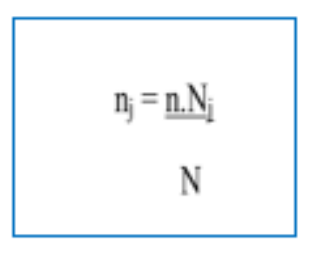

nj - sample size in j nursing school

$\mathrm{n}$ - Estimated final sample size

$\mathrm{Nj}$ - Total number of students in $\mathrm{j}$ nursing school

$\mathrm{N}$ - Total students in the schools

$\mathrm{n}=\mathrm{n} 1+\mathrm{n} 2+\mathrm{n} 1+\mathrm{n} 2 \ldots$ is the total sample size $(179)$

$\mathrm{N}=\mathrm{N} 1+\mathrm{N} 2+\mathrm{N} 1+\mathrm{N} 2 \ldots$ is total population size (373) (Figure-1).

\section{Variables}

Dependent Variable

Challenges of student nurses in clinical setting.

Independent Variables

Socio demographic characteristics (age, sex, ethnic group, marital status, religion, institution learn in and others).

Possible factors affecting clinical setting practice (individual student nurse factors, staff nurses factors, instructor factors, management factors, facilities/ clinical education factors and clinical practice competence related factors).

\section{Operational definitions}

Challenge: score range ranges 40 to 200 . 
By taking the median, higher score indicates a more challenges and less score indicates a less challenges in clinical setting.

With one item it was 3 , and with 40 items it was 120.

Data quality assurance procedures: The data was collected by 2 data collectors who were in their annual live time and received training for two day. Pretest done before the final data collection and consequently the instrument was checked before dissemination to the actual data collection sites, prior to selfadministered questionnaire and recording telephone interview; the objective of a study was verbally clarified for each participant.

Data collection tool and procedures: QUAN-Qual sequential explanatory design employed for sequencing of data and quantitative data was collected by self-administered English version questionnaire adopted from a related study and modified based on a prevailing context of nursing schools in Ethiopia to make it fit a study population (28). The content validity checked instrument has three sections. Section one: A socio demographic variables include (age, sex, institution name, marital status and others). Section two: closed ended item which assesse, challenge in clinical setting measuring questions includes 40 items in five dimensions, from nursing student 4 items, instructors 11 items, staff nurses 8 items, management 9 items, facilities and structures 8 items and Section three: 6 closed ended items for competency assessment. A quantitative tool has a 5 point Likert scale to represent a challenges in clinical setting to a topic scored on 5 point scale, i.e. 1(Strongly Disagree), 2(Disagree), 3(Uncertain), 4(Agree) to 5(Strongly Agree). Thus, possible score range were 40 to 200. By taking the median score, higher score indicates a more challenges in clinical setting and less score indicates a less challenges. The third section included 6 items for clinical practice competency assessment questions again have a 5 point Likert scale. A high score indicates better perception. A Pre-test was conducted taking $5 \%$ of sample size; those participants; who were learning in Selam Health College in Addis Ababa which was out of the randomly selected colleges for the main study. Pretest for telephone interview done on two participants who were not involved in main study taken from Rift Valley University. Piloting of the self-administrative questionnaire and qualitative items employed to identify difficulties, misinterpretations, feasibility of a study and a participants willingness to take part (34).

Qualitative data was collected with 8 open ended items via telephone interview using local language one week after quantitative data collection to minimize fatigue of participants. An open, flexible and inductive approach used to look for new insights into a phenomenon. Participants for the telephone interview were selected purposively from $3^{\text {rd }}$ and $4^{\text {th }}$ year nursing students, who have been clinical placement exposure above two sessions, and who was participating in quantitative survey and the data was collected up to the level of information saturation. The telephone interview was held after their preferable time (in their free time) in a quiet place and approximately bit took 12 to 20 minutes and recording voice of the interview was made after securing permission $(26,38,39,40)$.

\section{Results}


Socio demographic characteristics of the study participants in Quantitative Data

A total of 172 nursing students participated in the study making a response rate of $96 \%$. Of the 172 study participants, $123(71.5 \%)$ were female, and $133(77.3 \%)$ of them found in the age group 1825 years. From the total 172 study participants, majority $(108(62.8 \%))$ were orthodox religion followers and $69(40.1 \%)$ were from St. Mary health science college (Table-1).

Table 1: Socio demographic characteristics of Nursing students participated in the study $(n=172)$ 


\begin{tabular}{|c|c|c|}
\hline Variables & Frequency & Percent \\
\hline \multicolumn{3}{|l|}{ Sex } \\
\hline Female & 123 & 71.5 \\
\hline Male & 49 & 28.5 \\
\hline \multicolumn{3}{|l|}{ Age group } \\
\hline $18-25$ & 133 & 77.3 \\
\hline $26-34$ & 39 & 22.7 \\
\hline \multicolumn{3}{|l|}{ Religion } \\
\hline Orthodox & 108 & 62.8 \\
\hline Protestant & 31 & 18.0 \\
\hline Muslim & 22 & 12.8 \\
\hline Catholic & 11 & 6.4 \\
\hline \multicolumn{3}{|c|}{ Current Marital status } \\
\hline Single & 143 & 83.1 \\
\hline Married & 29 & 16.9 \\
\hline \multicolumn{3}{|c|}{ Learning institution } \\
\hline AAU & 23 & 13.4 \\
\hline St. Paulo's & 22 & 12.8 \\
\hline KYA Med & 58 & 33.7 \\
\hline St. Mary & 69 & 40.1 \\
\hline \multicolumn{3}{|l|}{ Entrance year } \\
\hline Third & 82 & 47.7 \\
\hline Fourth & 90 & 52.3 \\
\hline \multicolumn{3}{|c|}{ Residence ( $n=171)$} \\
\hline Dormitory & 17 & 9.9 \\
\hline Rental Home & 104 & 60.8 \\
\hline Other & 50 & 29.2 \\
\hline \multicolumn{3}{|c|}{ Substance use } \\
\hline Yes & 18 & 10.5 \\
\hline
\end{tabular}




\begin{tabular}{lll|} 
No & 144 & 83.7 \\
\hline
\end{tabular}

\section{Challenges Experienced by Nursing Students during Clinical Placement}

\section{Sources of the Nursing Student Challenges}

There are five parameters used to measure the challenge of the nursing students. Under each section, there are a number of questions related to each parameter. Because the number of questions differs from one section to the other, the researcher changed the total score of the students under each section in to percentage so that, can compare the score of one section against the other. The $1^{\text {st }}$ section is challenge score from the student side. There are 4 questions which measures challenge score from the student side making the total possible score from 5 to 20 unlike the second section (challenge score due to instructor factors) which have 11 questions making the total possible score from 11 to 55 . This way, individual scores under each section were compiled together by summing the scores and the total scores were changed to percentage accordingly. The following table illustrates median percentages for each sections with their interquartile range (IQR). We used median and IQR to measure central tendency and dispersion respectively because the distributions are not normal(Figure-2).

\section{Median Percentage Score of Nursing Students from different Factors to Estimate challenge score}

In this study median percentage score of nursing students from different sides used to estimate their challenge score. Among this factor with the nursing students had more challenged by instructor factors $(43.6 \%)$, and with nursing staff factor and facility factor; were in the same percentage of each factor( $40 \%)$ whereas with management factor( $37.8 \%)$ were challenged and less challenged by the nursing student factor which was (35\%) (Figure-3).

\section{Prevalence of Challenge among Nursing Students}

To determine the prevalence of nursing student challenge, 40 questions with Likert scale from different aspects used to estimate the challenge score were summed together and generated new variable. Each question having 5 item from strongly disagree (1) to strongly agree (5) make the possible challenge score from 40 to 200. The newly generated variable was dichotomized based on the score greater than the neutral response i.e. for one question to determine someone as having challenge, he/she should score more than 3 (the median) and for the total 40 questions, he/she should score above 120. As a result, those with a total score more than 120 were categorized as having challenged and the rest were categorized as having minimal or low challenge. After all, the prevalence of challenge among nursing students was found to be 29 (16.9\%). The prevalence among female was $17.1 \%$ and among AAU and St.Mery nursing students was $39.1 \%$ and $26.1 \%$ respectively (Figure-4).

\section{Factors associated with challenge of nursing students}

In the study, all the preliminary assumptions such as model fitness and multi collinearity were checked and found to be satisfied. Consequently, in bivariable logistic regression, students' religion, residence, 
entrance year, learning institution and substance use were found to have association with challenge among nursing students. However, after controlling the effect of confounding in multivariable analysis the final result confirmed that only substance use $[A O R=8.25(1.74,39.04)] 0.008^{*}$ and learning institution $[A O R=0.10(0.01,0.98)] 0.048^{*}$ were found to have significant association with nursing students challenge (Table-2).

Table 2: Bivariate and Multiplevariate Logistic Regression analysis of major areas of Factors associated with challenge among the study participants ( $n=172)$, Addis Ababa.2020

\begin{tabular}{|c|c|c|c|c|c|}
\hline \multirow[t]{2}{*}{ Explanatory Variables } & \multicolumn{2}{|c|}{ Challenge status } & \multirow[t]{2}{*}{ COR $95 \% \mathrm{Cl}$} & \multirow[t]{2}{*}{ AOR 95\% Cl } & \multirow[t]{2}{*}{ P-Value } \\
\hline & Yes & No & & & \\
\hline \multicolumn{6}{|l|}{ Learning institution } \\
\hline AAU & 9 & 14 & $1.82(0.67,4.93)$ & $0.18(0.01,3.62)$ & 0.266 \\
\hline St. Paul & 1 & 21 & $0.13(0.02,1.08)$ & $0.10(0.01,0.98)$ & $0.048^{*}$ \\
\hline KYA Med & 1 & 57 & $0.05(0.01,0.39)$ & $0.03(0.003,0.29)$ & $0.002^{*}$ \\
\hline St. Mary & 18 & 51 & 1 & 1 & \\
\hline \multicolumn{6}{|l|}{ Residence } \\
\hline Dorm & 9 & 8 & $7.54 \quad(2.61,21.80)$ & $15.91(0.81,312.45)$ & 0.069 \\
\hline Non-dorm & 20 & 134 & 1 & 1 & \\
\hline \multicolumn{6}{|l|}{ Substance use } \\
\hline Yes & 7 & 11 & $3.53(1.23,10.09)$ & $8.25(1.74,39.04)$ & $0.008^{*}$ \\
\hline No & 22 & 122 & 1 & 1 & \\
\hline \multicolumn{6}{|l|}{ Entrance year } \\
\hline Third & 17 & 65 & $1.70(0.76,3.82)$ & $1.18(0.44,3.12)$ & 0.745 \\
\hline Fourth & 12 & 78 & 1 & 1 & \\
\hline
\end{tabular}

*Statistically significant at $p$-value $<0.05 ; 1$ is Odds ratio for reference category.

\section{Association between the Challenge and Clinical Practice Competence}

This study revealed that there was statistically significant negative moderate correlation between students total challenge score and their overall competency score. [ $r=-0.672, \mathrm{P}$ value $=<0.001]$. This implies that as students challenge score increases, their competency score decreases. The bivariable logistic regression also supported this result. In the bivariable analysis, for each additional 1 score in the total challenge score, the odds that a nursing student will have good competency decreases by about $3 \%$ [OR= $0.9795 \% \mathrm{Cl} 0.96,0.99$, P value= 0.006] (Figure-5) 


\section{Challenge Characteristics of Study Participants in Clinical Setting}

Regarding in nursing staff communication the result of quantitative portion of this study $33(19.2 \%)$ of the participant was not motivated and about $24(14 \%)$ had difficulty in proper communication with staff nurses. And $12(7 \%)$ of the participants were challenged, in not adhere to the discipline of the nursing which also 21 (12.2\%) of the students had lack of proper communication with instructors. These aggravated with that of 103 (59.9\%) of the students perceive as the instructors were unfamiliar with practical method and was reported as they were absence at essential hours in the ward $126(73.3 \%)$.In addition they were working procedures in limited recourse/ equipment in the wards 88 (51.2 \%) (Table 3). 


\section{Table 3: Challenge Characteristics of Study Participants in Clinical Setting.}

\section{Dimensions of Challenges Items}

\section{Nursing Student Dimension}

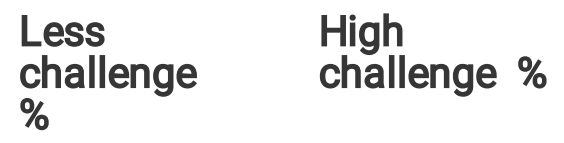

Lack of motivation in Nursing students

139

$(80.8 \%)$

Lack of proper communication between students and the ward staffs

Not adhering to order and discipline by the student

Lack of proper communication between students and instructor

\begin{tabular}{ll}
$148(86 \%)$ & $24(14 \%)$ \\
\hline $160(93 \%)$ & $12(7 \%)$ \\
\hline $\begin{array}{l}151 \\
(87.8 \%)\end{array}$ & $21(12.2 \%)$ \\
\hline
\end{tabular}

\section{Instructors Dimension}

Absence of experience instructor with a high academic level

Lack of suitable motivation in trainers

Emphasizing theoretical aspects in educational work

Not stating the educational objectives for students

Being unfamiliar with educational methods/practical

Absence at essential hours in the ward

Not assessing the students activities based on the clinical setting objectives by the trainers

Inadequate feedback to students

Referring heavy and difficult tasks to students

Lack of proper communication between students and instructor

Not emphasizing pre-study by trainers

\section{Staff Nurses Dimension}

Mismatch between the job of staff Nurses and scientific principles

Not implementing the process by the staff Nurses

Lack of physical and psychological preparation

Fatigue staff Nurses
157

$(91.3 \%)$

154

$(89.5 \%)$

155

(90.1\%)

$\begin{array}{cl}156(90.7 \%) & 16(9.3 \%) \\ 69(40.1 \%) & \begin{array}{l}103 \\ (59.9 \%)\end{array} \\ 46(26.7 \%) & \begin{array}{l}126 \\ (73.3 \%)\end{array}\end{array}$

$148(86 \%)$

$24(14 \%)$

$147(85.5 \%)$

$25(14.5 \%)$

$150(87.2 \%) \quad 22(12.8 \%)$

$146(84.9 \%) \quad 26(15.1 \%)$

$156(90.7 \%) \quad 16(9.3 \%)$

\begin{tabular}{ll}
$132(76.7 \%)$ & $40(23.3 \%)$ \\
\hline $129(75 \%)$ & $43(25 \%)$ \\
\hline $153(89 \%)$ & $19(11 \%)$ \\
\hline $147(85.5 \%)$ & $25(14.5 \%)$
\end{tabular}


Inadequate knowledge and skill

Not planning education to the patient in the daily task of nurses as a duty

Staffs uncooperativeness

Improper treatment of the staffs

Management dimension

Large number of students in internship groups

Discrimination between nursing students and the students of other medical sciences

The patient or their mates complaining about performing nursing activities by students

Unsuitable practical/ internship time

Mismatch between the objectives of clinical education and expectations of the hospital staffs

Shortage of time revealing in clinical setting

Not prioritizing education in the description of duties

Not gaining score for the nurse to train the patient

Mismatch between the number of patients and number of staff nurses

\section{Dimension of Facilities \& Structures}

Deficit of facilities and working conditions

Limited cases in the wards

Limited recourse/ equipment in the wards

The hospital being non-academic

Lack of access to the conference room

Poor educational planning

Not recognizing the role of nurses as teachers for patients and the society
$156(90.7 \%) \quad 16(9.3 \%)$

$137(79.7 \%) \quad 35(20.3 \%)$

$148(86 \%) \quad 24(14 \%)$

$139(80.8 \%) \quad 33(19.2 \%)$

Less challenge

$\%$

138

(80.2\%)

34 (19.8\%)

156

(90.7\%)

133

(77.3\%)

39 (22.7\%)

162

(94.2\%)

$10(5.8 \%)$

142

(82.6\%)

$30(17.4 \%)$

\begin{tabular}{ll}
$153(89 \%)$ & $19(11 \%)$ \\
\hline $141(82 \%)$ & $31(18 \%)$ \\
$\begin{array}{l}137 \\
(79.7 \%)\end{array}$ & $35(20.3 \%)$ \\
$\begin{array}{l}150 \\
(87.2 \%)\end{array}$ & $22(12.8 \%)$ \\
\hline
\end{tabular}

139

$33(19.2 \%)$

(80.8\%)

155

(90.1\%)

17 (9.9\%)

$84(48.8 \%)$

88 (51.2\%)

149

$23(13.4 \%)$

(86.6\%)

140

$32(18.6 \%)$

(81.4\%)

142

(82.6\%)

30 (17.4\%)

132

(76.7\%) 


\section{Result of Qualitative study}

\section{Description of Participants}

A total of 7 nursing students participated in the study, with four being in their fourth year level of study, and three in third-year level of study, within the four-year Bsc degree program. Prior to the telephone interviews, participants were requested to provide their demographic data which comprised age, sex, and language. There were 5 female participants and 2 males. Regarding language, seven of the participants were Amharic-speaking which used for the interview.

\section{Explored challenges experienced by nursing students during clinical placement}

Most participants in the qualitative study generally explain practical environment as it was the main part of nursing profession where theory changed to practice. In addition where was a place not to create incongruence between the teaching that occurs in the nursing colleges and the clinical experience practice that the nursing student experience within the clinical settings. According to most of the participants mention about practical setting; some participants had this to say:

"In my opinion practical area is a place which for nurses to develop our practical skill." (Participant 4, male, year 4, aged 25)

"Practical attachment is used to change theoretical learning to practical skill and which is basic to the profession" (Participant 2, female, year 3, aged 23)

"Practical attachment is one important part of the profession in learning of nursing profession. (Participant 1, female, year 4, aged 30)

"I Perceived Clinical area is where the theory changed to practice and we nurses where develop our practical skills." (Participant 3, female, year 3, aged 22)

Content was compared for similarity and differences, merged together, and categorize. Finally, themes were emerged. Below is a table that links the emerged themes with the categories that came forth from the data analysis: Seven themes emerged from the study (Table-4).

Table 4: Grouping of themes and categories of the participants.

Seven themes emerged from the study with their categories, which were as follows:

THEME 1: Student Nurses factors 


\begin{tabular}{|c|c|}
\hline Theme & Category \\
\hline \multirow[t]{5}{*}{ Student Nurses factors } & - Nursing student motivation \& responsibility \\
\hline & - Action takes place in practical area \\
\hline & - Student Nurses to resolving problems \\
\hline & - Developing Skill \\
\hline & - Internship students \\
\hline \multirow[t]{4}{*}{ Lack of role Model } & - Lack of support and guidance \\
\hline & - Staff Nurses Time \\
\hline & - Limited good practice in Staff Nurses \\
\hline & - Staff nurses action and reason \\
\hline \multirow[t]{5}{*}{ Instructors Responsibilities } & - Lack of support from Instructor \\
\hline & - Assessment of practical attachment \\
\hline & - Experience of Instructors \\
\hline & - Level of supervision \\
\hline & - Supervision \& Student responsibility \\
\hline \multirow{4}{*}{$\begin{array}{l}\text { Inadequate support Structure } \\
\text { \& Commination }\end{array}$} & - Nursing student action \& Responsibility \\
\hline & - Communication with patients \\
\hline & - Communication with Staff \\
\hline & - Student \& Instructor Communication \\
\hline \multirow[t]{3}{*}{ Lack of Equipment } & - Effect of inadequacy Equipment \\
\hline & - Available faculty equipment \\
\hline & - Tackling inadequacy of equipment \\
\hline \multirow[t]{4}{*}{ College Responsibility } & - Requirement from the college \\
\hline & - Affording to unfulfilled material \\
\hline & - New curriculum \\
\hline & - Benefits of Hospital Rotation \\
\hline \multirow[t]{3}{*}{ Time versus clinical practice factors } & - Practical attachment Schedule \\
\hline & $\begin{array}{l}\text { - Need \&Benefit of changing Schedule of practical } \\
\text { attachment }\end{array}$ \\
\hline & - Inadequacy of practical attachment time \\
\hline
\end{tabular}


Nursing students factor appeared to play a larger role in successful clinical learning followed by hospital factors(26). Study done in Ethiopia, assessed nursing students' attitude towards clinical practice and factors affecting student nurses' attitude towards clinical practice, results, revealed that $58 \%$ of student nurses have favorable attitude towards clinical practice(3)

"Clinical practice area was stressed for us, because it related with humane life. (Participant 2, female, year 3, aged 23)." I felt stress especially on first time exposure." (Participant 3, female, year 3, aged 22)

"It is mostly depend on the motivational status how much we could pass anxiety and doing things with unexaggerated stress." (Participant 7, male, year 4, aged 26)

Improper treatment, discrimination, inadequate knowledge and skill, and lack of communication skills with patients lead to stress and inferiority complexes in them(20).

"Patients were not volunteers to take care by student nurses even if we are exposed and develop confidence in the procedure; become anxious and felling stress to do procedures on first time even if I was shown the procedure repeatedly."(Participant 2, female, year 3, aged 23).

"Mostly in practical area when we face new procedures which is not familiar for us in doing so, I in my experience:" I, became anxious" in doing the procedure. "(Participant 3, female, year 3, aged 22)

"I try to tackle these from by referring and read more about and get insight about it."(Participant 5, female, year 4 , aged 27)

"Also this helps us/the nursing students to minimize our anxiety and stress and to build up more confidence in doing procedures in real patient." (Participant 6, female, year 3, aged 32)

\subsection{Category 1: Nursing student motivation \& responsibility}

Nursing student's independence and willingness to learn during the real practice period was revealed by some students as an important aspect for reaching optimum learning benefits during clinical placement. Some students said that "nursing students come into clinical settings with negative perceptions about the staff and are not motivated to engage with clinical responsibilities." Participants 1 and 2 explain further:

"Mostly they gave procedures which need labor force and which do not want to done by the staff nurses at the time." "Sometimes they are not patience when we ask them some unclear things in the procedures" (Participant 1, Female, year 3, aged 30)

I remember "one day of the first practical attachment, in surgical ward, the staffs instead of showing or guiding us to do procedures, they were fault finders in what we were doing." (Participant 2, female, year 3, aged 23) 
The above remarks agree with a study by Jamshidi \& Molazem et.al (2016) in Iran, where they investigated the factors that influenceof some staff nurses treated the students as messengers instead of learners. It was widely reported that student nurses were used for errands and were further tasked to do menial jobs instead of providing nursing care.

1.2 Category 2: Action takes place in practical area

The student nurse effort to fill the gap whenever" I found again the opportunity of doing the procedure again," (Participant 7, male, year 4, aged 26)

"The Doctors are not allowed us to practice in all procedures; mostly they are selective to students even to observe procedures instead they prefer staff nurses only." (Participant 6, female, year 3, aged 32)

I understand now is; "Nursing is not only take order from Doctors, However there were more part which have to be done of our parts even if there were more challenges. "(Participant 6, female, year 3, aged 32)

1.3 Category 3: Student Nurses to resolving problems

"Even getting access of internet which could help us to fulfill the gap by referring different source to the clinical practice skill, If not; since we are students to get access in money will be difficult for us." (Participant 4, male, year 4, aged 25)

"I expect to full fill this practical gap in the future in my carrier of nursing "which make me skilled, experience in practice." (Participant 7, male, year 4, aged 26)

\subsection{Category 4: Developing Skill}

"I think as we are not having much skill to do procedures, so patients were not willing to do procedures by the nursing students. "Sometimes they will be aggressive "also need to found some faulty doing." (Participant 2, female, year 3, aged 23)

"I have seen in practical area there are many limitations to become more skilled when you are student

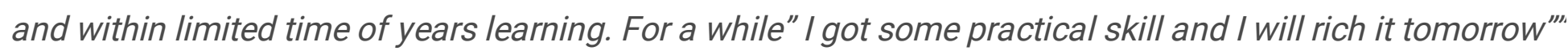
(Participant 7, male, year 4, aged 26)

"We students have to increase our motivation to ask and gain knowledge from Staff Nurses or Doctors as much as possible in practical attachment, and have to develop knowledge and skill." (Participant 4, male, year 4, aged 25)

"It is based on student's motivation. Even, I have first Diploma in Nursing I felt as have a gap in theoretical or practical part of the profession. And I want to be more grow in theoretical or practical aspect of OR specialization." (Participant 6, female, year 3, aged 32)

1.5 Category 5: Internship students 
"Related to other internship students, sometimes when they had round with senior Doctors; the seniors will not permit to us doing round with them." (Participant 3, female, year 3, aged 22) When they recognize as we are Nursing students and other reason given by them was the room is no enough for all of you internship like so on... "I felt as we discriminated"

"The hospital has to limit the nursing students who came for practice which accepted from collages, If we are too many there will be a chance for some students not to practice well. And also practical time exposure for the students will be short." (Participant 4, male, year 4, aged 25)

\section{THEME 2: Lack of role models}

The most common way in which students develop their own professional behaviors in relation to the delivery of care is through role modeling. Moreover, staff nurses need to recognize themselves as mentors and important stakeholders in the training of student nurses(20). In this theme, four categories emerged, namely Lack of support and guidance, Staff Nurses Time, Working Staff nurses out of scientific principle, Staff nurses action and reason, \& Communication with Staff.

\subsection{Category 1: Lack of support and guidance}

Awareness of Staff Nurses towards Nursing Student within clinical settings when nursing students are exposed to clinical practice is one part of becoming a role model. Clinical settings provide opportunities for nursing students to practice their clinical skills while being guided and supported by well-trained and experienced clinical staff who act as role models and increasing positive awareness towards nursing students. Nursing students reported that they need have more interaction with staff nurses as they are the ones who are most often at the patient's bedside. This approach eases the anxiety of students and assists them to adapt to the ward setup. Below is some negative remark by a student on how some staff nurses not properly guided and supported student nurses in the practical setting:

"Some staff nurses were not volunteer, to give us support and in creating individual confidence for the next time in doing the procedure. But I promise myself to be a good mentor in the future for the next nursing students when I join the nursing carrier." (Participant 2, female, year 3, aged 27)

In my opinion "I go through on a way of challenges in rising nursing skill in practical setting. "I read more and ask Nursing staff during the practical attachment depending on their willingness and free time and also ask our instructors if, they are present at the time" (Participant 2, Female, year 3, aged 27)

"The staff Nurses should not have loading us with only labor work like cleaning beds even walls in OR and the work not want to do and only to decreased their work load. "(Participant 1, female, year 4, aged 30)

"Staff nurses are not treated us; as we take their responsibility from them in the future of our carrier in nursing." (Participant 5, female, year 4, aged 27) 
2.2 Category 2: Staff Nurses Time

"Staff nurses they become busy and willing to show us the procedure taking adequate time." (Participant 4, male, year 4, aged 25)" I got more skill knowledge from our mentors of experienced nurses."

"Not volunteers to teach us, sometimes they are busy." (Participant 3, female, year 3, aged 22)

2.3 Category 3: Limited good practice in Staff Nurses

Nurse's student; who was also complaining about unprofessional behaviors of the staff nurses at the bedside, such as lack of cooperation, and unscientific nursing care expectations from them.

"Some nurse staffs not keeping the procedural way in practical area, I saw them not doing procedures based on scientific procedural way." (Participant 3, female, year 3, aged 22)

"The Staff Nurses work procedure not guided by scientific principle instead did in way of what they habituate." (Participant 6, female, year 3, aged 32)

"When we were in the ward it was wound dressing, but the staff nurse are not doing with sterility techniques. Mostly I and my calques students looked each other and felt confused." (Participant 1, female, year 4 aged 30) "I think there should be some communication or suggestion way to give them feedback."

"Our supervisors Instructors are present in the time; they could not have courage to influence the staff nurses not work out of scientific nursing procedure principle. So we become confused, when these procedures could mislead us." (Participant 2, female, year 3, aged 23)

"Staff nurses were knows; how they manage and handle student nursing, because it is a teaching hospital." (Participant 6, female, year 3, aged 32) "Communication prevents the nursing students not to habituate the same condition in nursing care procedure in future of their carrier."

"We are students could not tell them their mistakes, we need, an influence for us in doing in the right way and to keep for actual carrier in the future." (Participant 1, female, year 4 aged 30)

"Operation room is a room which needs highly sterility techniques, and obeys to wear gown, cape, mask... in the practical attachment or in doing procedures. This not gave emphasis in other wards." (Participant 1 , female, year 4 aged 30 )

2.4 Category 4: Staff nurses action and reason

"Even if some Staff Nurse of was not cooperative since they want use the time for themselves in practical area, like they show us fatigue but also most of them are cooperative even they discuss the procedure in the nursing office." (Participant 2, female, year 3, aged 22) 
"Staff nurses are our mentors, they need to create conditions to develop confidence in practical skill since we are joining the carrier and act on human life as long as we are in the profession, and also it has its own advantage in the development of the profession." (Participant 5, female, year 4, aged 27)

\section{THEME 3: Instructors Responsibilities}

According to the study Wambui WM, \& Githui SN.(2019) on Nurse Interns' Satisfaction With the Clinical Learning Environment: the maximum reported factor that enhanced clinical practice was effective supervision and assessment as stated by $32.3 \%$ of nursing students(13).

\subsection{Category 1: Lack of support from Instructor}

Insufficient supervision by clinical instructors, lack of equipment's, quality of practical assessment in clinical setting, and felt anxiety were some of the factors that delayed effective clinical practice(26)

The major challenges commonly experienced by student nurses usually involve; Incompetence of clinical instructors, Shortage of positive role model and effective supervision and assessment were pointed as challenge.

"Instructors need to give satisfactory orientation for each attachment practical area in entrance and ongoing follow-up and to gain recognition by patients."(Participant 5, female, year 4, aged 27)

"Instructors need to minimize our fear and anxiety in doing clinical practice, by support us in practical area." (Participant 3, female, year 3, aged 22)

"We start in demonstration and then to practical area followed by instructors and staff nurses." (Participant 1, female, year 4, aged 30)

"Instructors not follow us during practical attachment." (Participant 4, male, year 4, aged 25)

"Our instructors were always with us in practical area, we got sign from staffs and instructors for each procedure we did and assisted of procedures." (Participant 6, female, year 3, aged 32)

"Instructors must give attention more on detecting the needs of nursing students in clinical settings and schedule time to look through those needs. Therefore they need to deal quality-based skills and sited learning opportunities to nursing students during clinical practice. "(Participant 4, male, year 4, aged 25)

3.2 Category 2: Assessment of practical attachment

It is important to assign students to specific tasks as soon as they report to the hospital and these tasks should be evaluated at the end of the shift by a preceptor or clinical instructor(28).

"Evaluation was which "depend on only paper work not looked the practical attachment skill" (Participant 2, female, year 3, aged 23) 
"Some instructors give assignment in paper for practical attachment then they did not appear for a month in practical area .Since we doing in Human life Instructors should follow up our practical gap strictly." (Participant 4, male, year 4, aged 25)

"Although this condition seen as a gap there is also some Instructors evaluate students without consistent follow up and mostly students not evaluated adequately which given by the instructors." (Participant 5, female, year 3, aged 23)

3.3 Category 3: Experience of Instructors

This is common especially with novice clinical instructors. This is so challenging to student nurses when the staff nurses disagree both student and their instructor an opening to perform practical skill.

"As I have seen there were problems in getting experienced skill from our instructors, they also learn from the staff nurses. But they were efficient in the class theoretical learning with adequate teaching method. Such as giving assignment and we present it at bed side, got more knowledge with discussion." (Participant 4, male, year 4, aged 25)

"In applying theory to practice the main role of instructor is high since the Nursing students become novel for the place at first time. Hear in my experience the experience most of our instructors who were assigned for clinical practice were not have more than three years exposure of practical area or even they could join with their high GPA result by fulfilling the requirement conditions.". (Participant 4, male, year 4, aged 25)

"As I have seen in the college where; I learned some of supervisor instructors who are assigned in practical area they, themselves are not exposed more for practice when after they pass their first degree." (Participant 4, male, year 4, aged 25)

"Our Instructors was experienced even they have abroad the country like India, they were committed to guide us support in each and every part of the procedure." (Participant 6, female, year 3, aged 32)

\subsection{Category 4: Level of supervision}

The most reported factor that improved clinical practice was effective supervision and assessment as reported by $32.3 \%$ of participants(13).

"Instructors only present to take attendance in entry time and on the day off time." (Participant 3, female, year 3, aged 22)

"Some instructors give assignment in paper for practical attachment then they did not appear for a month in practical area .Since we doing in Human life Instructors should follow up our practical gap strictly." (Participant 4, male, year 4, aged 25) 
"Instructors have adequate knowledge in theory, but in practice they have some gaps, that arenewly Nurses who join teaching in nursing, who do not possess solid clinical experience. Some of them do not monitor us firmly the nursing students in practical area, only check for attendance, I mean;just check if the students are present at the clinical area." (Participant 2, female, year 3, aged 23)

"Instructors who assigned in the practical setting should pass more time with the student to look through the gaps in the skill." (Participant 5, female, year 3, aged 23)

"Instructors should not be present to take students attendance only. They have to present with us during the practical attachment period." (Participant 2, female, year 3, aged 23)

"Some of them most of the time are present at patient bed side. And for some of them we feel like they did not care for the practical area, because they not coach us." (Participant 2, female, year 3, aged 23)

"Once suddenly in a day, if they got us standing or read using internet, they think as we didn't done any procedure in a day and they evaluate us without considering the work done when they are not present and could give us low evaluation mark." (Participant 3, female, year 3, aged 22)

"Because after the collage assigned in the clinical area most of the time there is no strict supervision either from our instructors or the hospitals." (Participant 4, male, year 4, aged 25)

\subsection{Category 5: Supervision \& Student responsibility}

Student's factors with responsibility seemed to play a bigger role in successful clinical learning followed by hospital based factors(26). According to Study done in Botswana show that nursing students not successful to relate theory into practice because they deficiency suitable supervision in the clinical setting which effects to low capacity in their clinical practices(6).

"Our supervisor instructors or the staff nurses have to recognize and make us willing to give care and show us their responsibility for the profession." (Participant 7, male, year 4, aged 26)

"The staff nurses or our instructors should give moral and build our confidence by standing near to us every time when we want to do, Since we took responsibility in the future carrier of nursing from our present mentors." (Participant 2, female, year 3, aged 23)

"Whereas, some were present even in the night duty of the nursing students when we assigned working in the ward." (Participant 4, male, year 4, aged 25)

"When we asked some question further they are not volunteers to respond properly; instead they respond to us "it is not your part, you are nursing student need to know more to the profession, say; this is extra education." (Participant 3, female, year 3, aged 22)

"It was also having many difficulties especially when there is no person who mentors us in the area." (Participant 5, female, year 3, aged 23) 


\section{THEME 4: Inadequate support Structure \& Commination}

Nurses capability is to deal with on the knowledge and skill taught to them(1).Nursing education is composed of two harmonizing parts: theoretical training and practical training. A vast part of nursing education is sustained out in clinical environments(3).

Nursing is a practice-based profession. Therefore clinical education is an vital part of the undergraduate nursing curriculum(3).Nursing students require effective clinical settlements to allow the use of theory to practice (21). As stated in Zenani(2016) study done in Cape town south Africa; Acceptable college social setting enhanced clinical skill as stated by $85.4 \%$ of participants while $20.5 \%$ stated decent interpersonal relationship and collaboration among students increased student confidence, other things of a decent college social situation on clinical practice(21).In this forth theme, four categories emerged that influence a support Structure within a clinical setting, namelyNursing student action \& Responsibility, Communication with patients, Communication with Staff and Student \& Instructor Communication. The finding, of this study participant tells a situation;

\subsection{Category 1: Nursing student action \& Responsibility}

The student nurses usually found them unable to decide between the demands of their instructor and practicing nurses in real clinical situations and are unable to generalize from what they learnt in theory. "These are not one way problem all responsible bodies in the Nursing profession have to tackle the problems. "And we nursing students have to be responsible for what we are learning and have more exposure to skill."(Participant 4, male, year 4, aged 25)

4.2 Category 2: Communication with patients

"The challenge related to unable to create confidence with Patients in nursing student is depends on our good approach and commination and empathy which we gave to the patients." (Participant 4, male, year 4 , aged 25)

"And patients want us to communicate their health problem, especially if we are available most of the time at the bedside during practical attachment." (Participant 4, male, year 4, aged 25)

"Communication with patients was good when we were in a good approach to them, listening when they told us their problem related to the disease or other socioeconomic problem, and gave them some advice and reassurance." (Participant 2, female, year 3, aged 23)

"Some patients; when they looked; how we are doing with confidence they were more inclined to believe in what we are doing." (Participant 4, male, year 4, aged 25)

"However I in my experience having good approach and communication, in creating a good rapport and relation, If the patients looked us anxious in doing procedure, they try to support us by show willingness to work with feeling free and confident. "(Participant 4, male, year 4, aged 25) 
"Because, we have responsible in the future for each and every thing what we will do in human life. Like Universities; with a teaching hospital most of my practical experience was there. Mostly patients were assessed by different batch and profession including Nursing students ;"I saw that patients were became unwilling to be examined repeatedly by students, and even they say; I do not want to touch by students." "(Participant 3, female, year 3, aged 22)

\subsection{Category 3: Communication with Staff}

Ineffective communication, inadequate preparation, and emotional reactions are Iranian nursing students' challenges in the clinical learning environment(20) In study done in Ghana Among the clinical instructor factors and staff-student interaction factors were significantly associated with clinical practice competency(3)

"Staff nurses and the Instructors should communicate related to the gap in practical skill of the nursing students." (Participant 5, female, year 4, aged 27)

"I try to practice more even in the night by making decent communication with staff nurses, which give me a benefit to be more skilled with much more procedures than got in regular day working time. "(Participant 4, male, year 4, aged 25)

\subsection{Category 4: Student \& Instructor Communication}

"Especially private colleges need to be assessed by concerned body; how they follow their students in practical area, because I have seen there are many challenges related to inadequate follow-up and supervision in developing skills and integrating knowledge with practice." (Participant 5, female, year 4, aged 27)

"We have a good communication with other internship students; like medical doctors, doing together procedures like; NGT insertion and urine catheterization." (Participant 2, female, year 3, aged 23)

"First of all, when I join the profession with grate wants to be a Nurse. "So it based on each student initiation to get opportunity of practical skill and read more and became efficient in knowledge and skill. "I have to know what been asked by the patients, and know what I am doing? Because, I saw that students could not get; full support from the university or facility or Instructors." (Participant 4, male, year 4, aged 25)

\section{THEME 5: Lack of Equipment}

Availability of learning Equipment is base for clinical practical learning; also the participants perceive that their Clinical learning environment had rich learning experiences to provide sufficient learning experiences. However, most participants affirmed that despite the adequate numbers of conditions in the clinical learning environment there were inadequate material and as a result it did not support their learning effectively. 


\subsection{Category 1: Effect of inadequacy Equipment}

According to Aragaw et al. $21.9 \%$ of nursing students reported lack of teaching/learning resources such as equipment for nursing care procedures(30).

"We learn the ideal things but when we go to the clinical area we were unsuccessful to do the practice because of the resources, conservation of gloves, and equipment's in doing different procedure such as enema..." (Participant 3, male, year 4, aged 27)

"The equipment's in which we are doing is not standard and in some Governmental Hospital even picking up forceps is not available and instead Nurses use sterile glove to pick up sterile equipment's or gauss." (Participant 4, male, year 4, aged 25)

"The hospital seat up was not adequate related to equipment even like doing bed bath." (Participant 2, female, year 3, aged 22)

5.2 Category 2: Available faculty equipment

According to Aragaw et al. theory versus practice related equipment means that at times students performed procedure by shortcut opposing to the theory learned in class and availability of modern skills laboratory for demonstration was (42.4\%)(30).

"Most of the staff nurses are economical in using gauze, gloves and "we have difficulty in changing gloves from one patient to another patient in doing procedure."' (Participant 5, female, year 3, aged 23)

"Shortage of equipment's and the equipment's were not found as we learned in theoretical part.

(Participant 4, male, year 4, aged 25) And even the available equipment's are used repeatedly and are old. Some staff nurses initiate us to do practice more within available equipment's."

"I got the opportunity to look some procedures which was; I did not expect the procedures done in developing country like Ethiopia; in my experience like.' cardiac catheterization." (Participant 4, male, year 4 , aged 25)

"Our university full fill the necessary gown, what we challenged is in consumption of the hospital resource like glove, mask... which because assigning of many students in one ward or OR, there was complaints from the staffs." (Participant 1, female, year 3, aged 30)

5.3 Category 3: Tackling inadequacy of equipment

The approaches of successful clinical skill with lack of equipment suggested by students include frequent use of skills laboratory (62.5\%), participation in nursing conferences in the hospital (18.7\%), use of simulation (12.5\%), and watching nursing procedures videos to gain more skills $(6.5 \%)(30)$.

Some of the justifications provided to this were: 
Participant 7 give emphasize "for benefit of hospital rotation in relation to limitation of equipment's, so it is depend on hospital set up to the nursing student in addition to their motivation to get adequate skill in clinical practice."

"Even if it is not much coasty to afford the equipment's by the hospital, what I saw, is to buy the equipment for bed bath by the patient attendant." (Participant 2, female, year 3, aged 22)

\section{THEME 6: College Responsibility}

Participant 2 and 3, stress requirement from the college which could difficult in affording to fulfilled material like gowns they mention which is one reason for some students attached lately in practical attachment, in addition if the department makes student nurses to get more recognition and acceptance if we dress T-shirt like colure full uniform for both male or female students to differentiate from other internship health students.

\subsection{Category 1: Requirement from the college}

Participant 2 added some suggestion in choosing or recruiting to join nursing field, better to assess individual student interest to join the field in order to get more motivated professional in nursing in future carrier. That was;

"To get more motivated and companionate nurses in the carrier of nursing it is basic to choose or recruited to join the field starting from entering to the learning to the field." (Participant 2, female, year 3, aged 23)

\subsection{Category 2: Affording to unfulfilled material}

Most of student nurses (84.4\%) agreed that parent's economic status affected clinical practice(27).During they attach clinical practice, as stated by them it affect clinical practice and create psychological difficulties. The social climate of the school was significant in allowing student nurses in clinical learning(27).

"Our collage first of all did not fulfill uniform gown for nursing students when they attach practical area."(Participant 2, female, year 3, aged 23).

"We ought to buy with our money. For some Nursing students became one Couse to join the practical attachment lately after weeks. "(Participant 2, female, year 3, aged 23)

\subsection{Category 3: New curriculum}

Regardless of the allocation times for clinical placements of 4-7 weeks, some participants indicated the time was not adequate, implying that the participants failed to focus on clinical learning(29).Despite enhanced curriculum, nurses graduating from nursing colleges are not experienced enough to deliver the quality care to patients in most hospitals (25).this idea not agree; 
with some Participant 1 and participant 6, mentioned that" it is better to reinforced the new curriculum Which is some collage accept and uses for specific field specialization .i.e practical schedule every six months alternate with theoretical learning."

\subsection{Category 4: Benefits of Hospital Rotation}

Another challenge that hindered adequate acquisition of clinical skills by students was too many students versus number of patients in the clinical area. It was reported by many students and this was summarized by one of them who said this;

"Depends on the individual student Nurse acceptance .I got more trained in skill when we rotate in different hospitals or health facility, which we could get in one hospital which could not found the equipment and procedure in other hospital. (Participant 7, male, year 4, aged 25) This helps us to tackle the challenge related to unavailability of equipment's."

\section{THEME 7: Time versus clinical practice factors}

According to studies by Chipwaza et al.(2019),students frequently complain that they do not spend enough time in clinical areas to feel comfortable implying that the participants failed to focus on clinical learning(29).

\subsection{Category 1: Practical attachment Schedule}

The limitation of clinical training hours and lack of appropriate time with related theory or exam and regulations challenges students during skills acquirement.

"It was a period; after we took fundamental nursing written exam, when I remember the exam difficultness, I hope it was preferred, if we were took the exam after the practical attachment;

because when we talking each other of our exposure for different cases; it gave us to recognize our mistakes in the exam." (Participant 2, female, year 3, aged 23)

7.2 Category 2: Need \& Benefit of changing Schedule of practical attachment

The attachment Schedule planning for learning nursing competencies is not appropriate thus a big challenge to student nurses. "A student mentions that, in a week, they are expected to be in the hospital and still be prepared for theory exam sometimes, creating to them felt anxious, tired and try to work over by high outcome anticipations in a short period."(Participant 2, female, year 3, aged 23)

"Nursing Students have to continue attachment of clinical practice in July, instead of gave rest to us. This helps us to act more practice procedures to become skilled." (Participant 4, male, year 4, aged 25)

"Which help us to get more time and exposed for more skill and procedures, also I suggest it is better to alternate the theory and practice at all after second year of learning." (Participant 2, female, year 3, aged 
7.3 Category 3: Inadequacy of practical attachment time

Study done in Malawi (2019) indicated that the 4-7 weeks period the $34 \%$ of participants indicated that this period was not adequate for learning(27).Whereas in this study some participants respond; "Time, given for practical attachment is in my opinion is enough; "(Participant 6, female, year 3, aged 32) "I think the time given to the practical attachment is enough." (Participant 1, female, year 4, aged 30 )

"Simulation practice rooms are better to be open in weekend, to practice and apply easily in actual human life." "The time given for practical attachment was not enough". (Participant 4, male, year 4, aged 25)

"We have to use our time purposefully, No challenge free learning, so we have to be ready for the future challenges even in our carrier of Nursing." (Participant 4, male, year 4, aged 25.

\section{Discussion}

In the study, the prevalence of challenge among nursing students was found to be 29 (16.9\%). However, it is lower than the study conducted in Hawassa University, south Ethiopia in which the prevalence of clinical practice competency was found to be $25.2 \%(16)$.Also; it is lower than the study conducted in study perceived clinical competence among undergraduate nursing students in the university of Gondar and Bahir Dar University, Northwest Ethiopia revealed that overall $48.7 \%$ of the study participants perceived themselves as competent(30).The possible reason for the variation is due to the difference in the characteristics of the study participants. Some studies included only public learning institutions and others included only private institutions; in addition not done in similar region. However, in this study both public and private learning institutions were included.

Substance abuse was identified as one of the major associated factors of nursing students challenge in the study and the result confirmed that the odds of having challenge for study participants who were substance users were 8.25 times higher than those who were not substance users. [AOR $=8.25,95 \% \mathrm{Cl}$ $1.74,39.04]$. The possible justification for this association might be due to the fact that substance users are less likely to comply with the standards of teaching learning process which might have potential to develop negative attitude in those who teach them such as instructors and nurse staffs towards the substance users and the resulting challenge.

The other significantly associated factor was learning institution of the respondents. The finding of this study revealed that the percent odds of facing challenge for those who were learning in Saint Paul had $90 \%$ lower than those learning in Saint Mary [AOR $=0.1095 \% \mathrm{Cl} 0.01,0.98]$. Similarly, the percent odds that nursing students from KYA MED were having a challenge were $97 \%$ less than that of Saint Mary nursing students $[\mathrm{AOR}=0.0395 \% \mathrm{Cl} 0.003,0.29]$. This implies that these two learning institutions namely St Paul (public) and KYA MED (private) are using relatively favourable practical education system for their students. Whereas study done in Iran Benha public Hospital had the highest mean score of problems 
that faces Nursing interns during internship year than Private Hospitals (17), was the highest level of total obstacles present at Benha University were (65.3\%).

On the other hand, in this study, student's religion, marital status, sex, residence, age, and entrance year had no statistically significant association with the nursing students challenge. It might be due either lack of a true association or due to lack of adequate power associated with small sample size in this study. The other result which implied; there was statistically significant negative moderate correlation between students total challenge score and their overall competency score. $[r=-0.672, P$ value $=<0.001]$ thus need of student to have assessment in competency to identify the factors as shown in study conducted in Ethiopia; students with clinical practice assessment checklist most likely had ability to clinical practice competency by 4 times $(A O R=4.058,95 \% \mathrm{Cl} 1.238,12.65)$ than student who haven't got clinical practice assessment checklist during clinical practice(16).

In this study most participant mention that as practical attachment was used to change theoretical learning to practical skill however they also pointed challenges, in line with this in the study of Fiker (2016)quantitative result regarding clinical placement conduciveness for clinical practice, majority of the respondent $246(71.4 \%$ ) was disagree(16).Other side of qualitative result implies, it is one of the teachers' major responsibilities to treat nursing students properly in the practical area, to create higher Nursing student motivation \& give responsibility for learning as well as increasing their self-confidence thus, regarding instructor uses of continuous assessment during clinical practice, quantitative result showed (44.9\%) of participant disagree, but less in other study(21.2\%) strongly disagree as indicated in Fikre(2016)(16).In this study regarding nursing staff communication the result of the quantitative portion of this study showed $19.2 \%$ of the participant was not motivated and about $14 \%$ had difficulty in proper communication with staff nurses.

For action takes place in practical area and in doing Student Nurses to resolving problems Wambui et al. (13)revealed in their study that proper treatment and formation of a communication with students was an important item for nursing teachers to be a role model for students. This agrees with less percentage $7 \%$ of the participants were not adhering to the discipline of the nursing which also $12.2 \%$ of the students had lack of proper communication with instructors.

These intensified with that of $59.9 \%$ of the students perceive as the instructors were unfamiliar with practical method. In addition in qualitative result for the students had challenged in developing skill and doing with other Internship students, where as in the quantitative result 19.8\% participants mentioned there were no large number of internship students in the practical area. Related to the patients or their attendants complaining about performing nursing care by the nursing students the participant perceived as a challenge was $22.7 \%$. Even if the participants recognize only $12.8 \%$ there were mismatch between the number of patients and number of staff nurses. According to qualitative study done in Iran (2018) many of the students participating in the study complained about the staff's discrimination between them and students of medicine(17). In line to the same idea in this study some participants mentioned that as they feel discriminated when not allowed participation in patient rounding with students of 
medicine. However quantitative result of this study only $9.3 \%$ were pointed as they face discrimination between them and the student of other medical science. The comparison between nursing and medicine and regarding medicine as a superior major violates nursing students' personal dignity and gives them a sense of professional inferiority as one participant said in qualitative result "I felt as we discriminated".

Students' inadequate preparation for entering the clinical environment creates problems for them and nursing teachers(27). Even though they learn the fundamentals of nursing in classrooms and practice rooms, about $11 \%$ of the participants nursing students do not have sufficient time to practice and repeat these skills to completely enter the practical area and had shortage of time in revealing in clinical setting. And $5.8 \%$ participants were said; the time was unsuitable for practice, related to this; as mentioned in qualitative result which was some time was needed before the basic subjects in developing more understanding of the procedures linked to theoretical understanding. Rafiee and Moattari found that the students' deficient practice and lack of skill before arriving the clinical environment created problems for them with respect to learning in the practical setting(35).It is also important to have the students followed by experienced clinical instructors to ensure the best learning results (3).

Thus, the result aligns with this study, that challenges of nursing students were deeply assessed with respect to instructors, which showed that even if lowest percent $8.7 \%$ of participants said that instructors were had not had high academic level an experience, however $73.3 \%$ the student nurses pointed that the instructors were absent in essential hours in the ward. These results are consistent with the results of qualitative result also mention that only they were appear in the time of entry and day off time to check attendance of the nursing students. According to Kamphinda et al. study done in Malawi indicated that clinical supervisor's preparedness, motivation and attitude, and competence greatly affect students' clinical experiences(27), this agree on the results of this study showed $14.5 \%$ instructors had inadequate feedback to students with $12.8 \%$ of the participants were challenged referring heavy and difficult tasks with lack of as $9.3 \%$ who also perceive as the instructors not emphasis pre-study of the nursing students, and above these were more challenged $15.1 \%$ in lack of communication with the instructors.

In the present study, the $23.3 \%$ of the nursing students felt that there was mismatch between the job of the staff nurses and scientific principles and related to this about $25.5 \%$ also express as they were not implemented the nursing process. In accordance with this; that participants perceive $11 \%$ of them as the staff nurses could had lack of physical and psychological preparedness and $14.5 \%$ of them the staff nurses as they had fatigue. This result was congruence with Safan and Ebrahim study which Student nurses were also apprehensive about the problem that due to the shortage of positive role model, individual providers cannot learn and deliver the best caring approach(17).Maintenance and guidance were stated as deficient from both academic staff who controlled clinical as well as the staff nurses(6). Also stated that the most vital influencing factors were in adequate academic and practical preparation(17).Though the present study participants mentioned about $9.3 \%$ of the staff nurses had inadequate knowledge and skill but more of the participants $20.3 \%$ said staff nurses not plan education to the patient in the daily task as a duty. In addition more of $19.2 \%$ participants acquired improper 
treatment from the staff nurses and also $14 \%$ of participants said the staff nurses were not cooperative to give them their experience of skill.

Concerning the management of the hospital in this study, $20.3 \%$ of study participants had problems related to not gaining score for the staff nurses so as to train the student nurses. Over the median; $51.2 \%$ of the study participants indicated that there was a challenge in limited resource equipment in the Hospitals. This showed that participant were more challenged than study done Aragaw et al. (2019) on students towards clinical practice and its associated factors in Northwest Ethiopia which indicated 22.9\% of students stated shortage of equipment for accomplishment of procedures within the hospital and shortage of well-resourced skills laboratories as an significant factors have an effect in clinical practice(30).

Some of around $21.5 \%$ participants mentioned there was uncooperativeness of the patient and neglected education and about $23.3 \%$ participant felt not recognizing their role by the instructors to the patients and the society. As in the qualitative result of this study participant mentioned that the effective communication skills are taught to students before they enter the clinical environment with the emphasis on the differences between the clinical environment and the classroom environment as well as simulation lab, the quantitative result was reported $17.4 \%$ had poor educational planning and $18 \%$ were perceive challenged, in not prioritizing education in the description of duties with $19.2 \%$ said that as they challenged with deficit of facilities and working conditions even if there is lowest challenged result showed 9.9\% in limited cases in the ward. In the same way other qualitative study Aragaw et al.(2019) done directed that students who had good communications with clinical staffs, prepared well for clinical practice, practiced in well-equipped hospital, and accompanied frequently by clinical-supervisors in a clinical setting had a favorable attitude towards clinical practice(30).

As a conclusion the quantitative result showed in each factor median percentage the nurse student's challenge score were estimated. Among this factor with the nursing students had more challenged by instructor factors (43.6\%) which is in line with nurse instructors must have the core to attend and able to communicate successfully with their students(26).And with nursing staff factor and facility factor; were in the same percentage of each factor( $40 \%)$ whereas with management factor $(37.8 \%)$ were challenged and less challenged by the nursing student factor which was (35\%.).

In the qualitative study generally explain practical environment as it was the main part of nursing profession where theory changed to practice. In addition where was a place not to create incongruence between the teaching that occurs in the nursing colleges and the clinical experience practice that the nursing student experience within the clinical settings.

According to most of the participants mentioned about challenge faced during practical attachment; the emerged theme were Student Nurses factors, Lack of role Model, Instructors Responsibilities, Inadequate support Structure \& Commination, Lack of Equipment, conditions related the College Responsibility challenge and in using Time versus clinical practice factors were the student nurses challenged issues. 
From seven emerged theme in Student Nurses factors, as some participant said related to stress "Clinical practice area was stressed for us, because it related with humane life" Similarly other study mention that; the students stated that the first 2 months of their clinical placement were anxiety provoking for them(6).

Lack of role Model, as students reported that they need have more interaction with staff nurses however were challenged as participants said "Some staff nurses were not volunteer, to give us support and in creating individual confidence for the next time in doing the procedure. This is in line with the study in Tanzania support from the qualified nurses in the wards; this was because of poor nurse-student relationships, the unwillingness of staff nurses to teach(29).

The other theme was Instructors Responsibilities, the most reported factor that improved clinical practice was effective supervision and assessment whereas as the participant said "Some instructors give assignment in paper for practical attachment then they did not appear for a month in practical area .Since we doing in Human life Instructors should follow up our practical gap strictly." In addition they emphasis as some of them said "Instructors need to minimize our fear and anxiety in doing clinical practice, by support us in practical area." In line with this other study in Ethiopia Majority of the student believed that availability of clinical supervisor is useless, supervisor doesn't add any value for our clinical rather than checking our presence in practice site."(16).

In a theme of Inadequate support Structure \& Commination; they mention that "Staff nurses and the Instructors should communicate related to the gap in practical skill of the nursing students." Since Nursing education is composed of two harmonizing parts: theoretical training and practical training. Similar study done in Ethiopia, in focus group discussion student expressed that, "clinical supervisor in general have less ability to interact with staffs and they lack confidence to do certain procedure in front of the staff and student" (16).

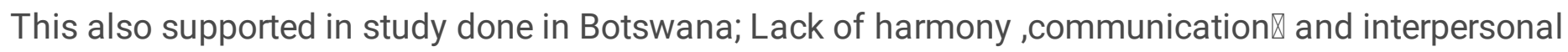
relationship between the educator and the student negatively affect the clinical learning(6).

Related to Lack of Equipment, they reported such as "Most of the staff nurses are economical in using gauze, gloves and "we have difficulty in changing gloves from one patient to another patient in doing procedure."Also in other study majority of the students mentioned that non-availability of the necessary equipment, sterile packs impact their clinical practice and force them to make up/create in providing care for the Patient $(6,21)$ in Botswana and South Africa supports these findings.

And in a condition related the College Responsibility challenge some of the participant reported "The hospital has to limit the nursing students who came for practice which accept from collages, If we are too many there will be a chance for some students not to practice well. And also practical time exposure for the students will be short." in line with this Study done in Iran the highest percentage of study subjects had mentioned their; if they were many students; problems faced during was, high consumption related insufficient resources (17). 
Finally the emerged theme was in using Time versus clinical practice factors were the student nurses challenged issues even if some participants said "the time is not enough" but some of them mentioned that "We have to use our time purposefully, No challenge free learning, so we have to be ready for the future challenges even in our carrier of Nursing." In other similar study only $48 \%$ indicated that the 4-7 weeks period was adequate for learning, while $34 \%$ of the participants indicated that this period was not adequate for learning and only $3 \%$ said that the period was too long for learning(27).

\section{Conclusion}

In conclusion, the prevalence of nursing students challenge in their practical education was found to be reasonable. There was moderate negative correlation between the students challenge score and their competency score which indicates the negative effect of the students challenge on their competency level. Therefore, the statistically significant factors should be considered in the effort made to reduce the students challenge level and to improve the quality of practical education.

The present qualitative study result identified the challenges experienced the participants when applying theory into practice in a clinical setting. The nursing instructors and clinical facilitators must involve in clinical settings, to assist students in linking theory with practice via guidance as the quantitative result indicated higher percentage the student nurses participants pointed they are being challenged because of instructors were absent in essential hours. Working on reduction of substance use among students demanded to reduce the challenge resulting from the substance use and to improve the competency students.

\section{Abbreviations}

AAU-Addis Ababa University

BSc-Bachelor of Science

CLE -Clinical learning environment

ETB-Ethiopian Birr

FGD -Focus Group Discussion

GC- Gregorian Calendar

HWs-Health Workers

IQR- Interquartile Range

IRB - Institutional Review Board

OR - Operation Room 


\section{Declarations}

\section{Acknowledgement}

We would like to extend our appreciation and gratitude Addis Ababa University for creating the opportunity to conduct this study.

Funding: not applicable.

Availability of data and materials: The datasets generated and/or analyzed during the current study are not publicly available for because of to avoid any kinds of misuse by the public before publication but are available from the corresponding author upon reasonable request.

Consent for publication: not applicable.

Competing interest: No competing interest.

Authors' detail: Almaz Addisie ${ }^{1}$ (BSc, MSc), Adult health nurse at Addis Ababa university. Mail address: almaz.addise@aau.edu.et.

Amsale Cherie2 (BSc, MSc, PhD), Associate Professor at Addis Ababa University college of health sciences. Mail address: amsale.cherie@aau.edu.et.

Debela Gela ${ }^{3}$ (BSc, MSc), lecturer at Addis Ababa University college of health sciences. Mail address: debela.gela@aau.edu.et.

Bizuayehu Atinafu Ataro ${ }^{4}$ (CN, BSc, MSc), lecturer at Wolaita Sodo university, College of Health Science. Mail address: bizuayehu.atinafu@aau.edu.et.

Authors' contribution: AA conceive the data and designed the study, supervised the data collection, performed the analysis, interpretation of data. BAA drafted the manuscript. AC and DG Assisted in designing the study, data interpretation and critically reviewed the manuscript. All authors evaluated and approved the manuscript.

Ethical clearance and consent to participate: all experimental protocols were approved by Addis Ababa University Institutional Review Board (IRB-AAU), college of health science research committee with meeting number: 09/2012EC. Participants informed about the purpose of the study and their right to participate or to leave if they were not comfortable. Informed consent was obtained from all participants and their confidentiality including all rights reserved. All methods throughout a study were carried out in accordance with relevant guidelines and regulations.

\section{References}

1. Ibrahim A, Aly A. Clinical judgment among nursing interns. Clinical Nursing Studies. 2018;6(3). 
2. Tiwaken S, Caranto LC, David JJT. The real world: Lived experiences of student nurses during clinical practice. International Journal of Nursing Science. 2015;5(2):66-75.

3. Adjei CA, Sarpong C, Attafuah PA, Amertil NP, Akosah YA. "We'll check vital signs only till we finish the school": experiences of student nurses regarding intra-semester clinical placement in Ghana. BMC nursing. 2018;17(1):23.

4. Papastavrou E, Dimitriadou M, Tsangari H, Andreou C. Nursing students' satisfaction of the clinical learning environment: a research study. BMC nursing. 2016;15(1):44.

5. HEIDARI MR, NOROUZADEH R. Nursing students' perspectives on clinical education. Journal of advances in medical education \& professionalism. 2015;3(1):39.

6. Rajeswaran L. Clinical experiences of nursing students at a selected institute of health sciences in Botswana. Health Science Journal. 2016;10(6):1.

7. Muñoz-Pino IP. Experience of nursing students upon their first care encounter with terminally ill patients. Investigacion y educacion en enfermeria. 2014;32(1):87-96.

8. Alharbi AR, Alhosis KF. The challenges and difficulties of the nursing interns during their clinical internship in Qassim Region, Saudi Arabia. Saudi Journal for Health Sciences. 2019;8(1):6.

9. Rafiee G, Moattari M, Nikbakht AN, Kojuri J, Mousavinasab M. Problems and challenges of nursing students' clinical evaluation: A qualitative study. Iranian journal of nursing and midwifery research. 2014;19(1):41.

10. Ojo AA. The challenges of best practices and standards in nursing in Nigeria. Igbinedion University, Edo State Inaugural Lecture Series, 4th Igbinedion University Press, Okada. 2010

11. Parry M. Student nurses' experience of their first death in clinical practice. International Journal of Palliative Nursing. 2011;17(9):448-53.

12. Baraz S, Memarian R, Vanaki Z. Learning challenges of nursing students in clinical environments: $A$ qualitative study in Iran. Journal of education and health promotion. 2015;4.

13. Wambui WM, Githui SN. Nurse Interns' Satisfaction With The Clinical Learning Environment: A CrossSectional Study. 2019.

14. Papastavrou E, Dimitriadou M, Tsangari H, Andreou C. Nursing students' satisfaction of the clinical learning environment: a research study. BMC nursing. 2016;15(1):44.

15. Porter J, Morphet J, Missen K, Raymond A. Preparation for high-acuity clinical placement: confidence levels of final-year nursing students. Advances in medical education and practice. 2013;4:83.

16. Fikre R. Assessment of Factors Affecting Clinical Practice Competency of Undergraduate Health Science Students in Hawassa University, South, Ethiopia. Assessment. 2016;22.

17. Safan SM, Ebrahim RMR. Problems and Obstacles Facing Nursing Interns and Its Relation to Their Performance at Clinical Setting: A Comparative Study. American Journal of Nursing. 2018;7(6):304-

18. Getie A. Assessment of clinical practice competency and associated factors among graduating nursing students in universities of Amhara region, northern Ethiopia, 2018 GC: Addis Ababa Universty; 2018. 
19. Mekonnen S. Student Nurses' Attitude Towards Clinical Practice and Associated Factors in Hawassa University, Hawassa, Ethiopia, 2015: Addis Ababa University; 2015.

20. Jamshidi N, Molazem Z, Sharif F, Torabizadeh C, Najafi Kalyani M. The challenges of nursing students in the clinical learning environment: A qualitative study. The Scientific World Journal. $2016 ; 2016$.

21. Zenani NE. Challenges experienced by second and third-year nursing students when integrating theory into practice in a selected clinical setting in the Western Cape Province. 2016.

22. Behnam M, Kamran A, Savadpoor MT, Nasiri K, Khaki M, Ghassemi N, et al. The compatibility of the new undergraduate nursing curriculum with occupational needs from the viewpoint of the faculty members of some north and north-west Universities of Medical Sciences of Iran. Future of Medical Education Journal. 2018;8(4):39-45.

23. Alharbi AR, Alhosis KF. The challenges and difficulties of the nursing interns during their clinical internship in Qassim Region, Saudi Arabia. Saudi Journal for Health Sciences. 2019;8(1):6.

24. Parvan K, Hosseini FA, Bagherian S. The relationship between nursing instructors' clinical teaching behaviors and nursing students' learning in Tabriz University of Medical Sciences in 2016. Education for Health. 2018;31(1):32.

25. Oermann $\mathrm{MH}$. Teaching in nursing and role of the educator: The complete guide to best practice in teaching, evaluation, and curriculum development: Springer Publishing Company; 2017.

26. Tiwaken S, Caranto LC, David JJT. The real world: Lived experiences of student nurses during clinical practice. International Journal of Nursing Science. 2015;5(2):66-75.

27. Kamphinda S, Chilemba EB. Clinical supervision and support: Perspectives of undergraduate nursing students on their clinical learning environment in Malawi. Curationis. 2019;42(1).

28. Shadadi H, Sheyback M, Balouchi A, Shoorvazi M. The barriers of clinical education in nursing: $A$ systematic review. Biomedical Research. 2018;29(19):3616-23.

29. Chipwaza B, Nyangena E, Kalolo A, Mirisho R, Gemuhay HM. Factors Affecting Performance in Clinical Practice among Preservice Diploma Nursing Students in Northern Tanzania. Nursing Research and Practice. 2019;2019:1-9.

30. Aragaw Y, Sinishaw W, Daba W, Mekie M. Attitude of Nursing and Midwifery students towards clinical practice and its associated factors in Northwest Ethiopia: a cross-sectional study. BMC research notes. 2019;12(1):205.

31. Van Graan AC, Williams MJS. A conceptual framework to facilitate clinical judgement in nursing: A methodological perspective. health sa gesondheid. 2017;22(1):275-90.

32. Yonas Girma Tilahun, Alireza Nikbakht Nasrabadi,Mussie Alemayehu, Alula Teklu and Nadia Ali Muhammad Ali Charania 2016. "The International Journal of Current Research, 8, (02), 26828-26833.

33. Coyne E, Needham J. Undergraduate nursing students' placement in speciality clinical areas: Understanding the concerns of the student and registered nurse. Contemporary Nurse. 2012;42(1):97104. 
34. Thabane L, Ma J, Chu R, Cheng J, Ismaila A, Rios LP, et al. A tutorial on pilot studies: the what, why and how. BMC medical research methodology. 2010;10(1):1.

35. Eman T, Cowman S, Edgar A. A triangulation study: Bahraini nursing students' perceptions of nursing as a career. 2012.

36. O. Nyumba T, Wilson K, Derrick CJ, Mukherjee N. The use of focus group discussion methodology: Insights from two decades of application in conservation. Methods in Ecology and evolution. 2018;9(1):20-32.

37. Cyr J. The pitfalls and promise of focus groups as a data collection method. Sociological methods \& research. 2016;45(2):231-59.

38. Collins KM, Onwuegbuzie AJ, Jiao QG. A mixed methods investigation of mixed methods sampling designs in social and health science research. Journal of mixed methods research. 2007;1(3):267-94.

39. Onwuegbuzie AJ, Collins KM. A typology of mixed methods sampling designs in social science research. Qualitative Report. 2007;12(2):281-316.

40. Thompson AR, Chambers E. Ethical issues in qualitative mental health research. Qualitative research methods in mental health and psychotherapy. 2012:23-37.

41. Johnson S, Rasulova S. Qualitative impact evaluation: Incorporating authenticity into the assessment of rigour. Bath Papers in International Development and Wellbeing; 2016.

\section{Figures}




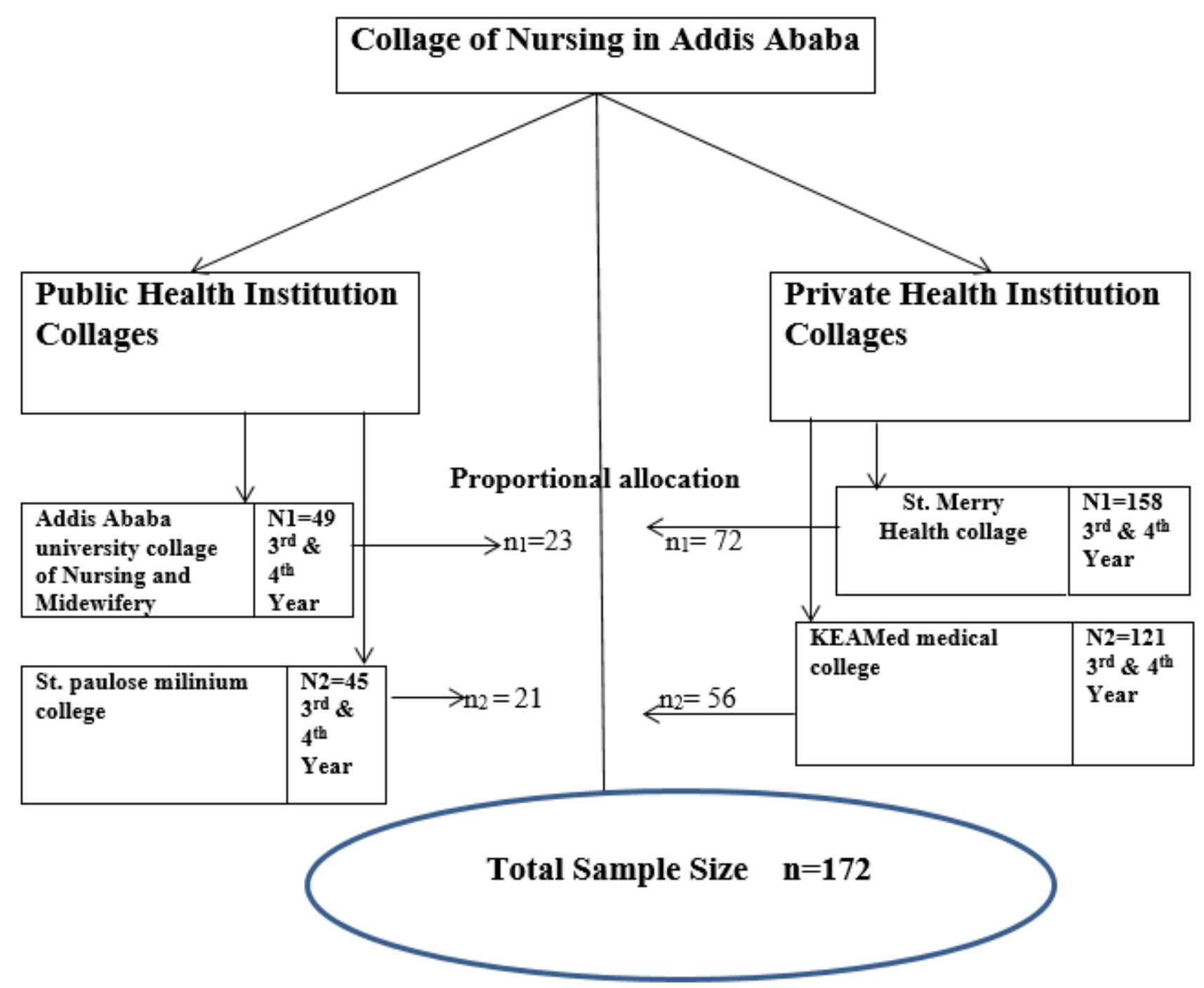

Figure 1

sampling procedure 


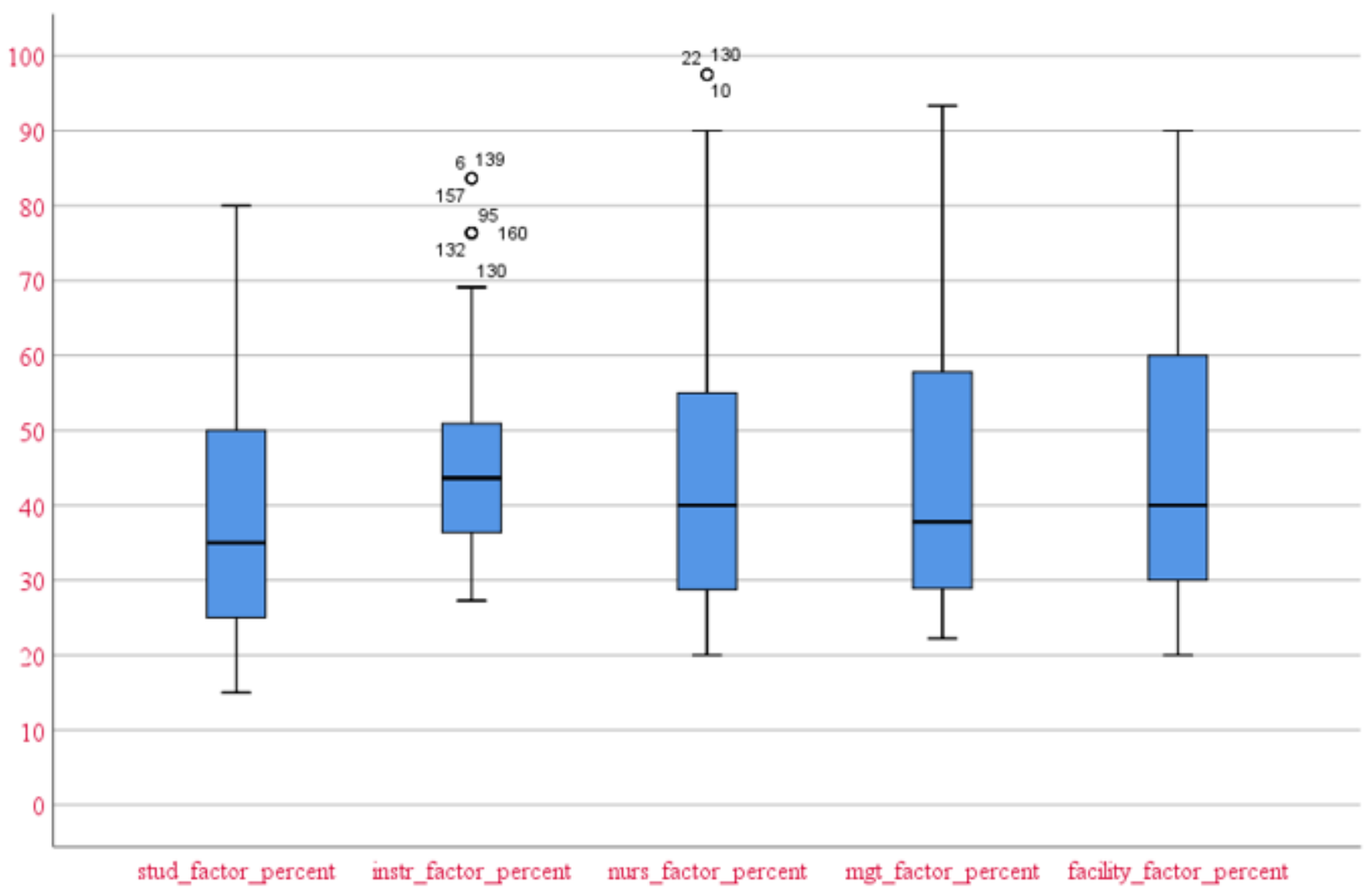

Figure 2

Box plot showing the percentage score of nursing students from different aspects used to estimate their challenge score. 


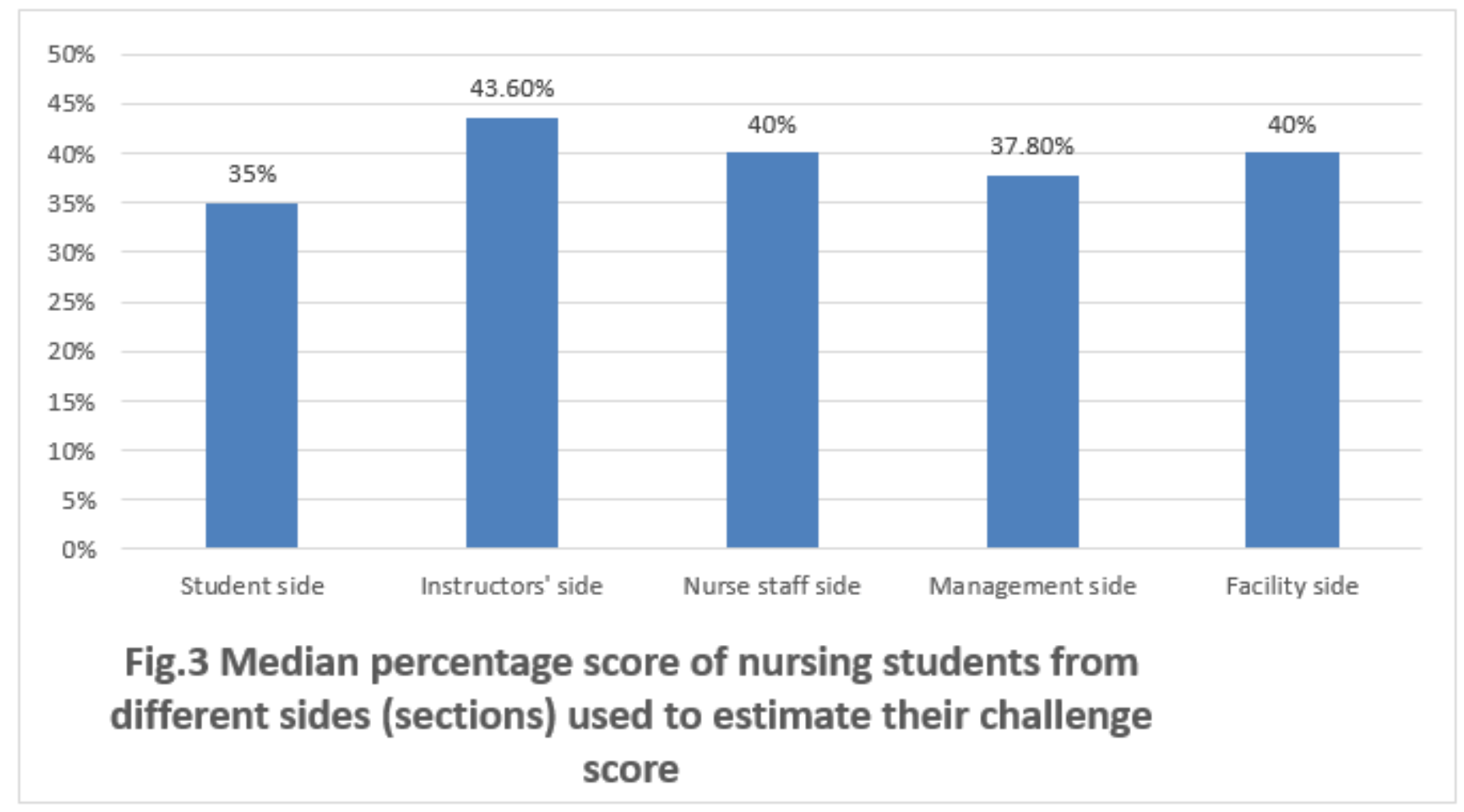

\section{Figure 3}

See image above for figure legend

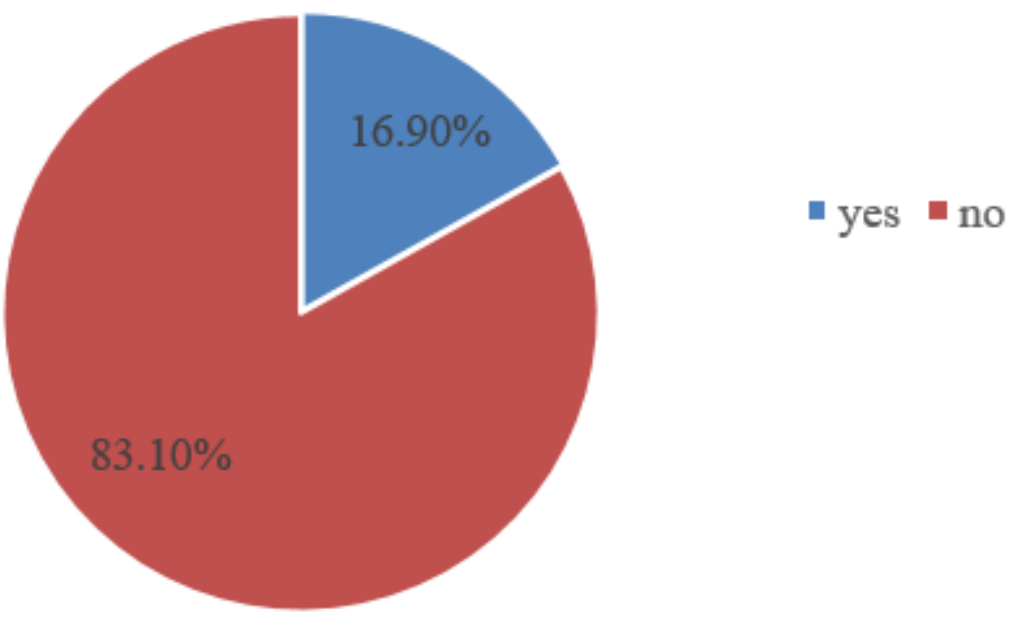

Fig. 4 Prevalence of Challenge among nursing students participated in the study

Figure 4

See image above for figure legend 


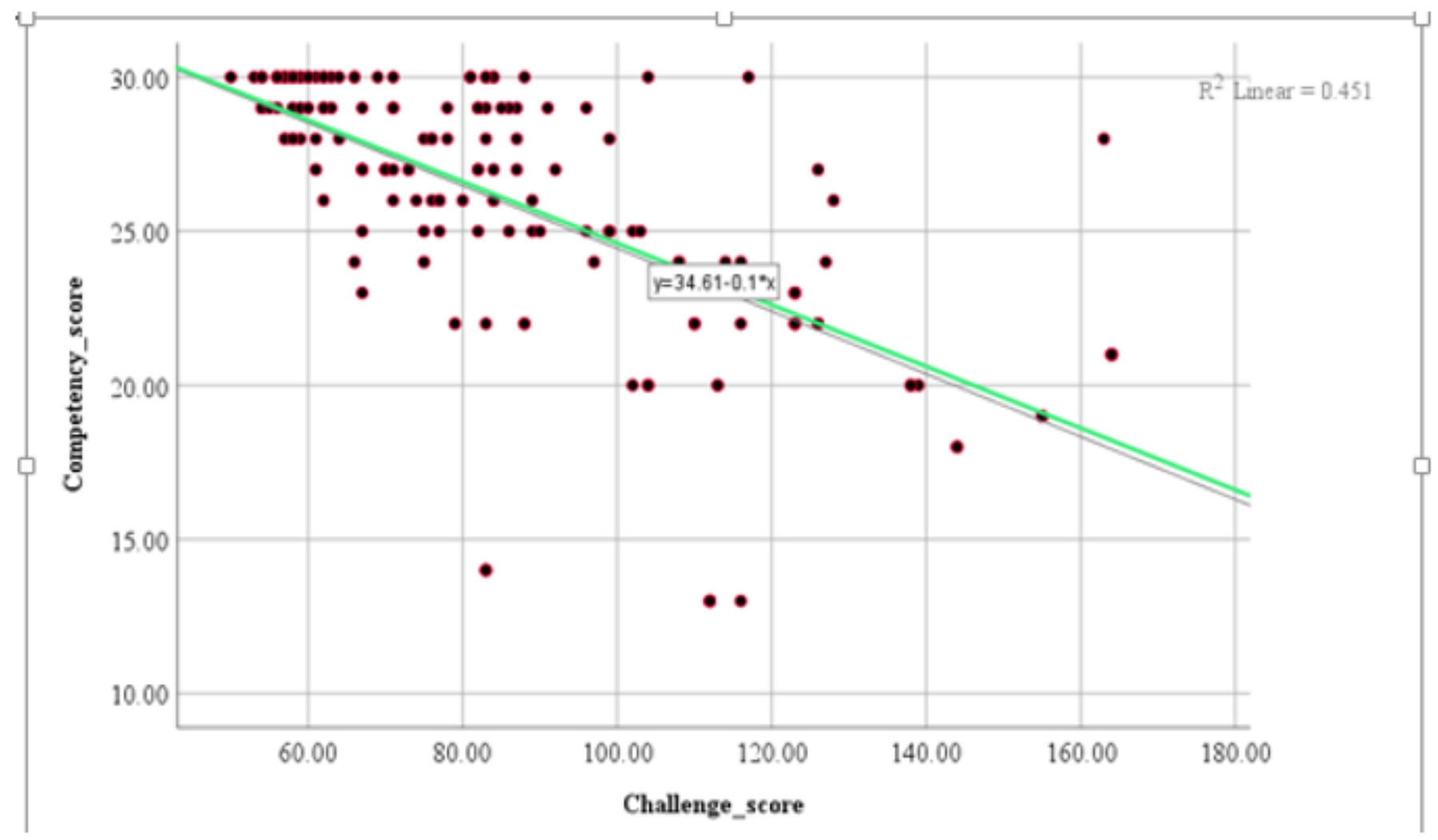

Figure 5

scatter plot showing the association between clinical competence and challenge of the participants. 